\title{
STEAM Teacher for a Day: A Case Study of Teachers' Perspectives on Computational Thinking
}

\author{
Anita JUŠKEVIČIENĖ \\ Vilnius University Institute of Data Science and Digital Technologies \\ Akademijos str. 4, LT-08663 Vilnius, Lithuania \\ e-mail: anita.juskeviciene@mif.vu.lt
}

Received: October 2019

\begin{abstract}
Computational thinking abilities development is a recent popular research topic. Teachers need support and examples of suiTable STEAM activities that focuses on CT implementation. For this purpose, possible class activities were presented for $\mathrm{CT}$ abilities development purpose. Teachers from different disciplines identified possible interconnections between presented activities and CT abilities. The case study results showed that primary assumptions were quite different from teachers believes as assumptions weakly correlate with five teachers opinions. The implication of these results is that it provides a better understanding of CT integration in education and is particularly useful for researchers interested in CT and its applications in different subjects.
\end{abstract}

Keywords: computational thinking, CT abilities, class activities, physical devices, STEAM.

\section{Introduction}

In order to guarantee modern learner employability and comply with the new digital society requirements, such as, basic, psychological, self-fulfillment, societal needs ${ }^{1}$, students should develop skills in accordance with digital age issues. Skills like, critical thinking, problem-solving, collaboration, communication and creativity (WEF, 2016). Thus changes in learning approaches are needed. Such as, computational thinking (CT) - an approach for solving problems that draws on concepts fundamental to computing (Wing, 2008) that has to offer numerous benefits within different education level, for teaching and learning process across different subjects (Zaki et al., 2019). However, there is no commonly accepted definition of CT (Fessakis, Prantsoudi, 2019). Furthermore, computational thinking fosters digital age skills, helps learners to understand the technology

\footnotetext{
${ }^{1}$ https://www . oxfordeconomics.com/recent-releases/digital-society-index-2019-humanneeds-in-a-digital-world
} 
they use every day (Lye and Koh, 2014). However, it is important not only to have the ability to appropriately use what others have developed before, but also to be capable of creating new tools, debugging and solving errors, sharing ideas with the others - abilities STEAM professionals aspire (Guenara et al., 2017). Researchers argue, that despite the obvious relevance of CT to informatics, CT needs to be taught in disciplines outside of this discipline (Psycharis, 2018). Computational thinking skills could be acquired by integrating STEAM disciplines and real life into education programs because an interdisciplinary approach supports meaningful learning (Conde et al. 2019, Bati et al., 2018). STEAM can be considered as an educational approach that consist of STEM (Science, Technology, Engineering and Mathematics) disciplines with Art and enhances students' inquiry skills, problem solving skills and creative thinking (Psycharis, 2018) that encourages hands-on experience and gives students the chance to gain and apply relevant, "real world" knowledge in the classroom.

The previous research on CT abilities development presented the most relevant class activities in the informatics and crafts lessons (Juškevičienè, 2019). However, it fails to answer if CT could be developed in other subjects in order to seek integration.

Also, as there is no accepted definition of CT, researchers often focus on the core components of CT. The framework of CT component groups was proposed based on literature review (Juškevičienè, Dagienè, 2018), however there is still an ample debate among scholars and educators about what it really means (Moreno-León et al., 2018) and it does not address the challenge to purify the core CT approach components.

The purpose of this research is the contribution to the integration of CT in education. The focus of this paper - to identify teachers' perceptions and believes of CT abilities implementation in the classroom. Toward this direction the case study at computing infused science workshop was conducted. The main discussed aspects fall into categories of teachers' perspectives on computational thinking abilities interconnections with class activities, and beliefs on the most important CT abilities.

The paper is structured as follows: Section 2 introduces the concept of computational thinking, main components of CT and learning activities. Section 3 covers the results of case study on teachers' perspectives and believes about suiTable class activities for particular CT abilities development. The paper ends up with conclusions.

\section{Computational Thinking in Classroom}

\subsection{Computational Thinking}

Computational thinking has a lot of definitions and some of them define it as ability to solve problems with algorithmic thinking or diverse human skills to do with problem solving, such as creativity, critical thinking and team work (Curzom, McOwan, 2017, p. 3; Krauss, Prottsman, 2017, p.47, CSTA\&ISTE, 2011; Grover \& Pea, 2013). However, neither unified definition nor set of CT components is still not accepted as researchers propose different definitions for CT based on their research context (Pöllänen, Pöllänen, 2019; Weigend et al., 2018). 
Computational thinking is often related to algorithmic thinking, programming, problem solving and STEAM. There are many tools and techniques for CT teaching application: in computerized or unplugged problem-solving process. Two main strategies are used for CT implementation (Moreno-León et al., 2018): unplugged activities (Weigend et al., 2018) (activities that involve logic games, cards, puzzles, strings or physical movements to get in touch with computer science concepts such as algorithms, data transmission or data representation) and computerized activities (such as, programming (Guenara et al., 2017): in arrow-based visual environments, in blockbased visual environments, using textual languages, connected with the physical world (Conte et al., 2019)).

In the book by Williams (Williams, 2017) stated that CT can be incorporated into any subject. The case studies with Bee-Bots, Code.org, Scratch and ARIS and how CT concepts can be applied to these tools are presented in detail. Furthermore, CT is being infused into curricula in a variety of STEAM subjects (Lytle et al., 2019).

The literature review was done by (Psycharis, 2018) in order to outline research studies in the different forms of STEAM integration and how CT can be used in this integration and what can support this approach. Such researches highlight the importance for teachers support as they meet variety of challenges, such as subject knowledge, differentiation (skills in), lack of time and support, approaches to teaching topics (pedagogy), students' understanding, and ability to problem solving (Sentance, Csizmadia, 2017). Support for teachers could be by providing appropriate content, methods, tools and curriculum for teaching and CT assessment in order to reach the positive learning outcomes. Usually educators assess elements, such as learners' abilities that are listed in the curriculum, as well as learners' interest or satisfaction (Mislevy, 2012). The suiTable CT abilities for this research are listed in Table 1. The list was developed based on the literature review on CT main components made by (Ju kevičiené, Dagienè, 2018). CT abilities were slightly changed, some were made of few combination (such as, abilities 4,10 ) and some were divided (such as, into 11 and 14, into 18 and 19) in order to apply to study. These abilities are sorted into eight dimensions:

- Data analysis \& representation that involves processes of data collection, analysis and representation;

- Computing Artefacts that involves process of designing and developing computational artefacts as well as applying computing techniques to creatively solve problems; Decomposition that involves process of breaking down the task into smaller manageable parts;

- Abstraction that involves process of the solution for a more general problem by ignoring certain details;

- Algorithms that involves process of algorithm design.

- Communication and collaboration that involves process of communication and work with others to achieve a common goal or solution;

- Computing \& Society that involves the process related to the influence of computing and its implications on individuals and society;

- Evaluation that involves the process of ensuring that a solution, whether an algorithm, system, or process, fit for the purpose. 
Most of these dimensions' abilities are common in other approaches, such as problem solving, programming, or constructionism.

Table 1

The list of CT abilities

CT abilities Abilities

dimensions

Data analysis \&

1. To gather appropriate information and making sense of data

representation

2. To depict and organize data in appropriate graphs, charts, words, or images

3. To identify the patterns and commonality between artefacts, processes or systems

4. To expand an existing solution for a given problem to cover more cases and to find similarities between items as a way of gaining extra information

Artefact

5. Create an artefact with a practical, personal, or societal intent

6. Select appropriate techniques to develop a computational artefact

7. Use appropriate algorithmic and information-management principles

Decomposition

8. To break down a problem (data, processes) into parts that are easier to manage or into constituent parts to make them easier to work with

Abstraction

9. Explain data, information, or knowledge represented for computational use

10. Explain abstractions used in computation or modelling, identify abstractions and describe modelling in a computational context and filtering information when developing solutions

Algorithms

11. Identify the processes and sequence of events

12. Plug pieces into an algorithm to help with a result

13. Control a process by automatic means in order to reduce human intervention to a minimum

14. Control a process by automatic means

Communication \& $\quad$ 15. Explain the meaning of a result in context

collaboration

16. Describe computation with accurate and precise language, notations, or visualizations

17. Summarize the purpose of a computational artefact

18. Help to another student in solving a computational problem, producing an artefact

19. 19 Ask for help from another student in solving a computational problem, producing an artefact

20. Share the workload by providing individual contributions to overall collaborative effort

21. Foster a constructive collaborative climate by resolving conflicts and facilitating the contributions

22. Exchange knowledge and feedback

23. Review and revise their work as needed to create a high-quality artefact

Computing \& Society 24. Identify impacts of computing, describe connections between people and computing

25. Explain connections between computing concepts

Evaluation 26. Evaluate a proposed solution to a problem

27. Locate and correct errors

28. Explain how an artefact functions

29. Justify appropriateness and correctness 


\subsection{Class Activities}

Based on previous researches (Juškevičienè, 2020; Juškevičienė, 2019) the appropriate class activities for CT development were chosen:

1. Theoretical introduction and class demonstration.

2. Lessons and tasks.

3. Modelling the Idea.

4. Poster.

5. Spreadsheet.

6. Presentation.

7. Artefact.

The theoretical introduction includes description of devices used, electric circuits, define main programming concepts definitions, introduce related CS concepts and interconnections between the scope and problems, examples of implementation, the impacts on society of computing. Class demonstrations includes projects examples of prototyping with Arduino in order to explain connections between computing concepts.

Each such lesson has eight parts: Title, Schema parts, Code, Explanation, Summary, Implementation in real world, It's informatics, Tasks. The purpose of tasks of each lesson is to determine what needs to be known. The aim of tasks is to explain connections between computing concepts. Such as, change the name of variable. Thus learner will be introduced with variable definition how to declaring variable rules: types, values. For evaluation implementation, tasks are also suiTable. Working with code in IDE Arduino coding environment debugging is possible as it gives the list of errors and identify the line of error made. Additionally, in order to gain ability to explain how an artefact functions, learner should understand the code used: what each line do, what should be changed in code order to perform the task.

Modelling the Idea - class activity is suiTable for investigation plan formulation. The task is to present the idea in one page by using images, schemas and any other suiTable visuals explaining what an artefact will be constructed, what materials will be used, what it will do. In order to model the idea, learners should be able to depict and organize data in appropriate visuals (e.g. image), also to identify the patterns and commonality between artefacts.

In order to present the investigation plan activity Poster could be used. Poster should help to identify the problem and strategies as well as refine the investigation plan. In the posters, groups should present the sequence of proposed product functioning process. Likewise, data flow diagram or algorithm, explaining data inputs and outputs, the process that changes the output.

On purpose to carry out the investigation plan learners should be able to decompose the problem into easier to manage parts and collect preliminary data. Thus, activity listing parts of artefact in Spreadsheet Table was proposed.

Project presentation is a group activity that involves presentation development in slides and making 15 minutes' oral presentation of whole group work with implemented project (tangible object) demonstration. The content of presentation is based on crafts subject school matura exam task. It should describe the purpose and usefulness of the product/ 
object, properties and selection criteria of materials used for product development, product technological solutions and safety of work. The main aims of presentation is to analyze and interpret the findings, draw conclusions, suggest solutions and recommendations.

Final projects (Artefact development) is based on class topics and any other related prototypes seen in class demonstrations or found online. The aim of such activity is to encourage group evaluation and reflection on process and product. Artefact development involves spreadsheet of artefact parts development, prototyping, testing and implementation.

All those activities were successfully implemented during teaching experiment at spring semester (February-May). The experiment took place at basic school, with eighth grades pupils both boys and girls. It took eleven lessons on informatics and crafts subjects. During the lessons learners were working with Arduino and were engaged in these activities for CT abilities development as well as informatics and crafts subjects' curriculum goals and objectives achievement. An in-depth discussion of the experiment, with learners, results is beyond the scope of this paper.

\section{Research Study}

Theory triangulation was used in quantitative (validation) and qualitative (inquiry) case study. In this case study thirteen teachers from different disciplines (national language, informatics, dance, crafts, physic, mathematics) and levels (pre-primary, primary, higher and vocational schools) were participating. They all are interested in and had experience on STEAM disciplines integration, and convinced that it could help improve learning thus they registered to one-day workshop on CT development by the hands-on experience (i.e. prototyping with Arduino) and participated in this case study as experts (convenient or purposeful sampling). It is believed that professionals from different disciplines bring different perspectives. And if each interprets the same information in the same way - then validity is established.

In order to identify teachers' perceptions and believes on CT abilities implementation in the classroom the case study at computing infused science workshop was conducted. The main discussed aspects fall into two categories: teachers' perspectives on computational thinking abilities interconnections with class activities, and beliefs on the most important $\mathrm{CT}$ abilities. The data was collected by using questionnaires after some activities implementation. The results were obtained after using quantitative and qualitative data analysis: correlation, mean and Kendall's W calculation.

\subsection{Teachers Evaluation on Interconnections between CT Abilities and Class Activities}

The teachers were divided into six groups. They were given identical tasks that simulate the activities of the experiment made at basic school on spring semester of 2019 (February-May). First of all, the presentation was made. The content of presentation included computational thinking definition and abilities presentation, the list of classroom 
activities for CT development. Next, the worksheets on one lesson example with tasks were distributed to teachers. In Fig. 1, teachers are performing (Fig. 1b) one of the tasks that was to construct the prototype of security alarm system based on printed schema (Fig. 1a). Additionally, each teacher got some basic information on Arduino prototyping kit objects, electrical circuits. After prototyping a security alarm system, the task was to model their own idea. Each group prepared the visualization of their idea how PIR (a passive infrared) motion detection sensor or any other sensors could be used in their projects. Some teachers propose projects with parts they worked with, and others included some extra modules, like RFID card and reader, sound detector (Fig. 2). Also,

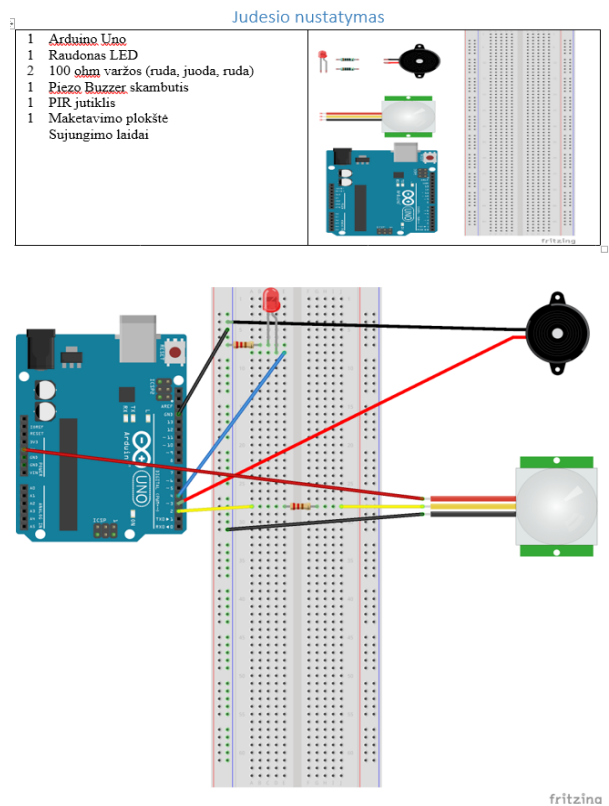

(a)

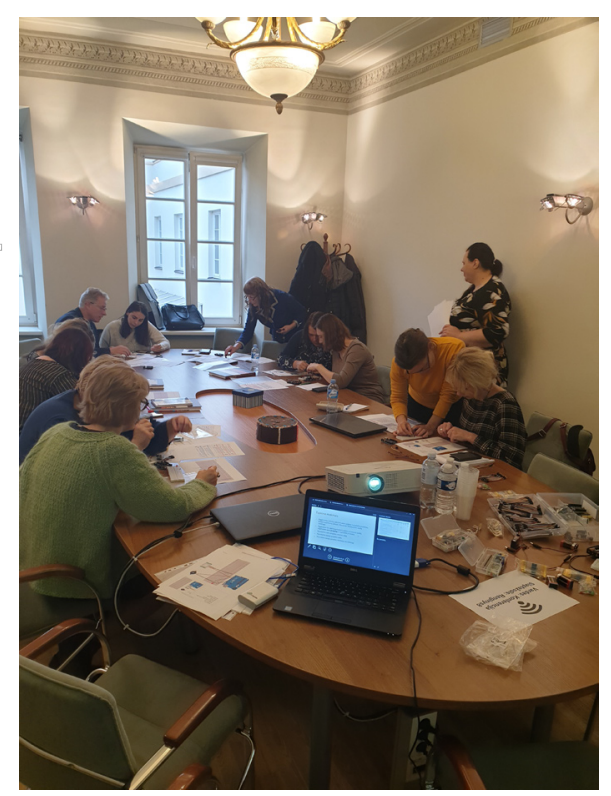

(b)

Fig. 1. Prototyping task: (a) schema and parts, (b) teachers performing the tasks.

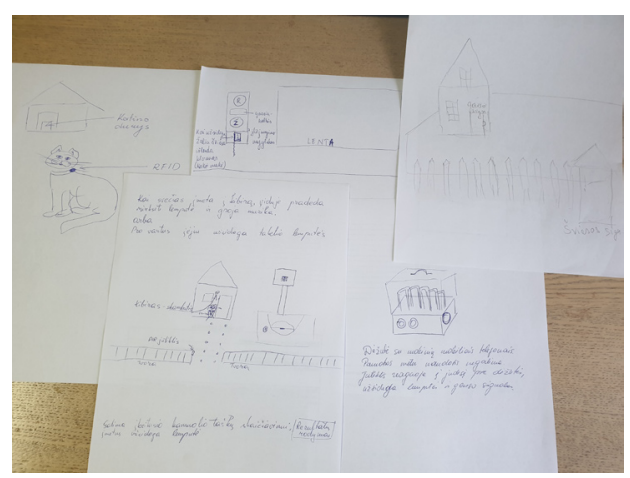

Fig. 2. Group projects ideas visualization. 


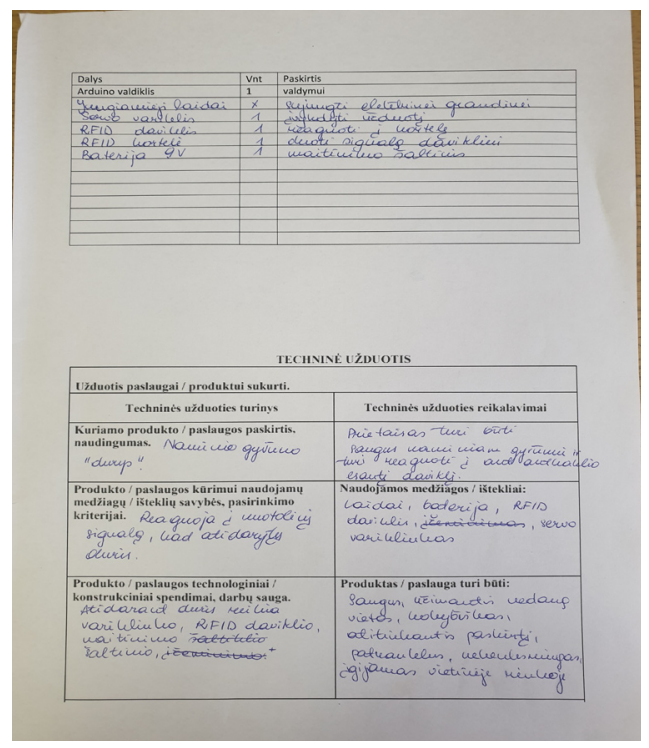

Fig. 3. Group projects worksheets.

they listed the necessary parts for their pretended projects and specified the purpose and usefulness of the artefact, properties and selection criteria of materials used for product development, product technological solutions and safety of work in worksheets (Fig. 3). At the final, each group presented their ideas and discussed the similarities and limitations of proposed ideas. The aim of all those tasks were to consolidate knowledge of presented possible class activities.

\subsubsection{Teachers'Perspectives on Computational Thinking Abilities Interconnections with Class Activities}

After all those activities presented above, teachers were asked to evaluate whether there are interconnections with each presented CT abilities or not using questionnaire. All twenty-nine CT abilities were listed, and not grouped. Also no prior interconnections were suggested.

Summary of all teachers' opinions is presented in Table 2. The given numbers in Table 2 are percentages of teachers agreeing on interconnections. Agreements that are more than a half are presented in bold. Colored boxes shows interconnections that match with this paper authors opinion. The authors' predicted links that were made in the informatics and crafts subjects context, are presented in (Juškevičienè, 2019).

Abilities from communication and collaboration dimension were prescribed as having the most links to the activities (four links at most), abilities from data analysis and representation, algorithms, computing and society, and evaluation dimensions each have two interconnections. Agreements between more than a half of teachers showed that there are no interconnections in abstraction dimension. 
Table 2

The mean in percent of teachers' opinion on CT abilities and class activities interconnections

\begin{tabular}{|c|c|c|c|c|c|c|c|c|}
\hline \multirow[b]{2}{*}{ 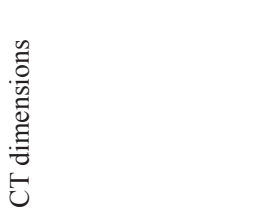 } & \multirow[b]{2}{*}{ 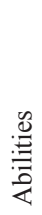 } & \multicolumn{7}{|c|}{ Class activities } \\
\hline & & 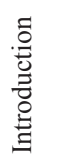 & $\frac{\sqrt[n]{n}}{\sqrt[n]{-1}}$ & 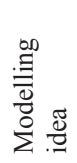 & $\stackrel{\vec{\Phi}}{0}$ & 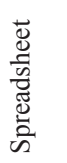 & 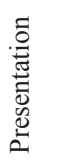 & 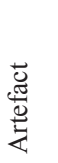 \\
\hline \multirow{4}{*}{$\begin{array}{l}\text { Data analysis \& } \\
\text { representation }\end{array}$} & & 46.2 & 53.8 & 46.2 & 38.5 & 30.8 & 69.2 & 46.2 \\
\hline & & 23.1 & 38.5 & 7.7 & 46.2 & 53.8 & 61.5 & 7.7 \\
\hline & & 7.7 & 15.4 & 38.5 & 23.1 & 0 & 15.4 & 38.5 \\
\hline & & 7.7 & 30.8 & 46.2 & 23.1 & 7.7 & 15.4 & 46.2 \\
\hline \multirow[t]{3}{*}{ Computing Artefacts } & & 7.7 & 23.1 & 61.5 & 15.4 & 7.7 & 15.4 & 46.2 \\
\hline & & 0 & 23.1 & 61.5 & 15.4 & 0 & 38.5 & 30.8 \\
\hline & & 15.4 & 46.2 & 76.9 & 30.8 & 15.4 & 15.4 & 23.1 \\
\hline Decomposition & & 0 & 61.5 & 38.5 & 15.4 & 23.1 & 30.8 & 38.5 \\
\hline \multirow[t]{2}{*}{ Abstraction } & & 30.8 & 46.2 & 30.8 & 15.4 & 46.2 & 30.8 & 38.5 \\
\hline & & 30.8 & 38.5 & 46.2 & 15.4 & 15.4 & 46.2 & 38.5 \\
\hline \multirow[t]{4}{*}{ Algorithms } & & 23.1 & 46.2 & 86.4 & 23.1 & 23.1 & 23.1 & 61.5 \\
\hline & & 15.4 & 38.5 & 69.2 & 15.4 & 0 & 15.4 & 61.5 \\
\hline & & 23.1 & 30.8 & 61.5 & 23.1 & 38.5 & 7.7 & 46.2 \\
\hline & & 23.1 & 61.5 & 69.2 & 7.7 & 23.1 & 23.1 & 46.2 \\
\hline \multirow{9}{*}{$\begin{array}{l}\text { Communication \& } \\
\text { collaboration }\end{array}$} & & 23.1 & 46.2 & 61.5 & 23.1 & 23.1 & 46.2 & 46.2 \\
\hline & & 38.5 & 46.2 & 38.5 & 23.1 & 23.1 & 38.5 & 30.8 \\
\hline & & 30.8 & 46.2 & 38.5 & 0 & 30.8 & 46.2 & 23.1 \\
\hline & & 53.8 & 76.9 & 69.2 & 38.5 & 38.5 & 38.5 & 46.2 \\
\hline & & 38.5 & 53.8 & 53.8 & 30.8 & 23.1 & 38.5 & 53.8 \\
\hline & & 15.4 & 30.8 & 30.8 & 53.8 & 30.8 & 46.2 & 61.5 \\
\hline & & 53.8 & 53.8 & 61.5 & 38.5 & 38.5 & 38.5 & 53.8 \\
\hline & & 15.4 & 30.8 & 46.2 & 23.1 & 15.4 & 23.1 & 46.2 \\
\hline & & 23.1 & 30.8 & 38.5 & 15.4 & 15.4 & 30.8 & 84.6 \\
\hline \multirow[t]{2}{*}{ Computing \& Society } & & 30.8 & 23.1 & 23.1 & 0 & 7.7 & 15.4 & 46.2 \\
\hline & & 38.5 & 53.8 & 53.8 & 23.1 & 30.8 & 30.8 & 46.2 \\
\hline \multirow[t]{4}{*}{ Evaluation } & & 23.1 & 46.2 & 53.8 & 15.4 & 7.7 & 15.4 & 38.5 \\
\hline & & 15.4 & 46.2 & 69.2 & 15.4 & 30.8 & 23.1 & 38.5 \\
\hline & & 30.8 & 46.2 & 30.8 & 7.7 & 0 & 23.1 & 69.2 \\
\hline & & 30.8 & 23.1 & 53.8 & 23.1 & 7.7 & 30.8 & 69.2 \\
\hline
\end{tabular}

There were also eight interconnections that no one teacher at all has indicated. Workshop participants think that spreadsheet activity is not suiTable for abilities 3, 6, 12 and 28 developments. Introduction has no connection to 6 and 8 abilities. 17 and 24 abilities could not be developed in the poster activity.

It is interesting to note, that more than 21 percent of interconnections (colored in green in Table 2 cells) indicated by teachers (the mean of total answers) overlapped with authors predicted links (number of total possible links: 203, number of predicted links: 66). 
Additionally, the statistical technique - correlation was used in order to show how strongly variables are related to each other. All correlations are presented in Table 3 .

First, the correlation between this paper authors opinion and each teacher's opinion was calculated. The results show that at $1 \%$ level of significance the magnitude of the association is very weak or negligible with two teachers (correlation coefficients: 0.181 (informatics teacher), 0.185 (national language teacher)), and weak with also two teachers (correlation coefficients: 0.223 (informatics and mathematics teacher), 0.276 (informatics teacher)) and at 5\% level of significance the magnitude of the association is very weak with one teacher (correlation coefficient: 0.139 (dance teacher)). Those five correlations are highlighted in blue in Table 3. It is not surprise, that three of them were informatics teachers with some prior knowledge on CT and algorithmic thinking. Such result leads to the assumption that absence of correlation with others teachers is due to

Table 3

Correlation of teachers' opinions

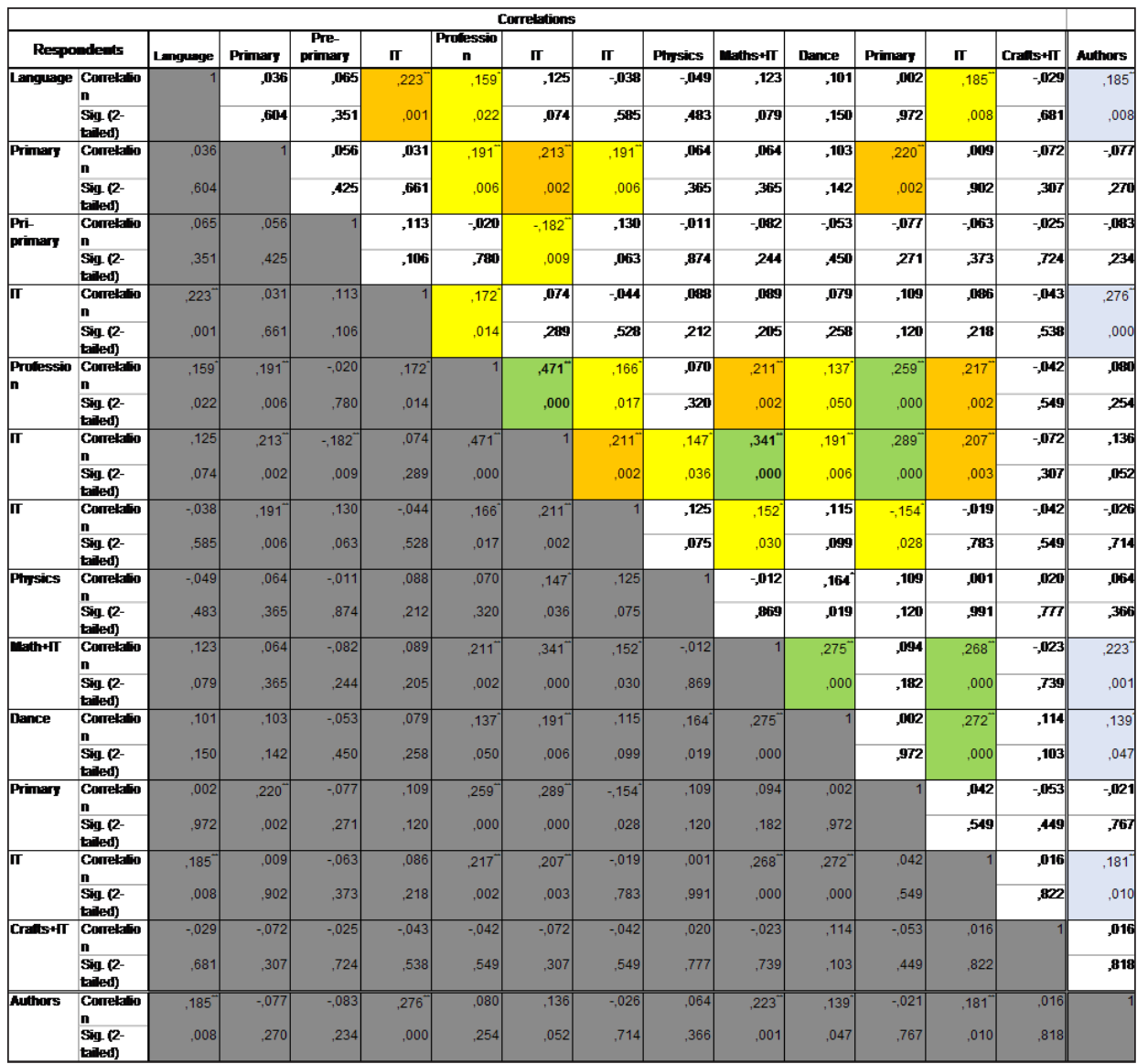

* Correlation is significant at the 0.05 level (2-tailed).

${ }^{* *}$ Correlation is significant at the 0.01 level (2-tailed). 
the lack of explanation on $\mathrm{CT}$ and abilities, or low understanding of CT relevance to other subjects than informatics.

Next, the correlation was explored between each participant. Results showed that the degree of association between teachers' opinions at $1 \%$ level of significance is strong positive (highlighted in green and by bold in Table 3 ) between profession and informatics subjects' teachers $(r=0.471)$ and moderate positive relationship between informatics and informatics \& mathematics teachers $(\mathrm{r}=0.341)$. Close enough meaning to moderate degree of association at $1 \%$ level of significance is between five pairs (highlighted in green in Table 3): informatics and primary $(\mathrm{r}=0.289)$; informatics \& mathematics and dance $(r=0.275)$; dance and informatics $(r=0.272)$; informatics \& mathematics and informatics $(\mathrm{r}=0.268)$; profession and primary $(\mathrm{r}=0.259)$. Weak positive relationship was identified in seven pairs (highlighted in orange in Table 3): language and informatics $(r=0.223)$; primary and primary $(r=0.220)$; profession and informatics $(r=0.217)$; primary and informatics $(\mathrm{r}=0.213)$; profession and informatics \& mathematics, as well as, between informatics and informatics subjects' teachers $(r=0.211)$; informatics and informatics $(r=0.207)$. In yellow

Moreover, in order to quantify how much these teachers, agree with each other the Kendall's Concordance Coefficient W was calculated. Kendall's W is 0.169. Thus teachers have a poor agreement with each other. Friedman chi-squared $=511,861$, df $=202$, $\mathrm{p}$-value $=0.0001$. Friedman chi-squared is higher than chi-squared distribution critical value 251.677 with 202 degrees of freedom, $\alpha=0.01$. Thus the null hypothesis can be rejected, the is agreement between teachers.

\subsubsection{Beliefs on the Most Important CT Abilities}

Ten participants of the workshop identified the abilities they are using at their classes (USED) and eight participants - the most relevant CT abilities (RELEVANT) (Table 4).

Table 4

Used in classes and the most relevant CT abilities

\begin{tabular}{llcc}
\hline $\begin{array}{l}\text { CT abilities } \\
\text { dimensions }\end{array}$ & Abilities & 10 & 6 \\
\hline $\begin{array}{l}\text { Data analysis \& } \\
\text { representation }\end{array}$ & $\begin{array}{l}\text { To gather appropriate information and making sense of data } \\
\text { To depict and organize data in appropriate graphs, charts, words, or images }\end{array}$ & 8 & 4 \\
& $\begin{array}{l}\text { To identify the patterns and commonality between artefacts, processes or } \\
\text { systems } \\
\end{array}$ & $\begin{array}{l}\text { To expand an existing solution for a given problem to cover more cases and } \\
\text { to find similarities between items as a way of gaining extra information }\end{array}$ & 8 \\
& & 8.25 & 3.5 \\
\hline
\end{tabular}




\begin{tabular}{|c|c|c|c|}
\hline $\begin{array}{l}\text { CT abilities } \\
\text { dimensions }\end{array}$ & Abilities & 离 & 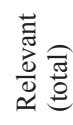 \\
\hline \multirow{3}{*}{$\begin{array}{l}\text { Computing } \\
\text { Artefacts }\end{array}$} & Create an artefact with a practical, personal, or societal intent & 2 & 1 \\
\hline & Select appropriate techniques to develop a computational artefact & 1 & 1 \\
\hline & Use appropriate algorithmic and information-management principles & 6 & 6 \\
\hline Mean & & 3 & 2.66 \\
\hline Decomposition & $\begin{array}{l}\text { To break down a problem (data, processes) into parts that are easier to } \\
\text { manage or into constituent parts to make them easier to work with }\end{array}$ & 4 & 4 \\
\hline Mean & & 4 & 4 \\
\hline \multirow[t]{2}{*}{ Abstraction } & Explain data, information, or knowledge represented for computational use & 3 & 5 \\
\hline & $\begin{array}{l}\text { Explain abstractions used in computation or modelling, identify abstractions } \\
\text { and describe modelling in a computational context and filtering information } \\
\text { when developing solutions }\end{array}$ & 1 & 2 \\
\hline Mean & & 2 & 3.5 \\
\hline \multirow[t]{4}{*}{ Algorithms } & Identify the processes and sequence of events & 7 & 5 \\
\hline & Plug pieces into an algorithm to help with a result & 5 & 5 \\
\hline & $\begin{array}{l}\text { Control a process by automatic means in order to reduce human } \\
\text { intervention to a minimum }\end{array}$ & 2 & 4 \\
\hline & Control a process by automatic means & 5 & 5 \\
\hline Mean & & 4.75 & 4.75 \\
\hline \multirow{9}{*}{$\begin{array}{l}\text { Communication } \\
\& \text { collaboration }\end{array}$} & Explain the meaning of a result in context & 8 & 5 \\
\hline & $\begin{array}{l}\text { Describe computation with accurate and precise language, notations, or } \\
\text { visualizations }\end{array}$ & 4 & 5 \\
\hline & Summarize the purpose of a computational artefact & 5 & 4 \\
\hline & $\begin{array}{l}\text { Help to another student in solving a computational problem, producing an } \\
\text { artefact }\end{array}$ & 8 & 2 \\
\hline & $\begin{array}{l}\text { Ask for help from another student in solving a computational problem, } \\
\text { producing an artefact }\end{array}$ & 8 & 2 \\
\hline & $\begin{array}{l}\text { Share the workload by providing individual contributions to overall } \\
\text { collaborative effort }\end{array}$ & 4 & 0 \\
\hline & $\begin{array}{l}\text { Foster a constructive collaborative climate by resolving conflicts and } \\
\text { facilitating the contributions }\end{array}$ & 4 & 0 \\
\hline & Exchange knowledge and feedback & 3 & 0 \\
\hline & Review and revise their work as needed to create a high-quality artefact & 5 & 3 \\
\hline Mean & & 5.44 & 3.5 \\
\hline \multirow[t]{2}{*}{$\begin{array}{l}\text { Computing \& } \\
\text { Society }\end{array}$} & $\begin{array}{l}\text { Identify impacts of computing, describe connections between people and } \\
\text { computing }\end{array}$ & 3 & 3 \\
\hline & Explain connections between computing concepts & 2 & 4 \\
\hline Mean & & 2.5 & 3.5 \\
\hline \multirow[t]{4}{*}{ Evaluation } & Evaluate a proposed solution to a problem & 4 & 2 \\
\hline & Locate and correct errors & 5 & 3 \\
\hline & Explain how an artefact functions & 4 & 6 \\
\hline & Justify appropriateness and correctness & 2 & 5 \\
\hline Mean & & 3.75 & 4 \\
\hline
\end{tabular}


As the CT abilities examined overlapping with abilities from other commonly used pedagogical approaches it was not surprise that the most selected abilities that are often used in classes were from data analysis and representation dimension (mean $\bar{x}=8.25$ ) and, communication and collaboration dimension $(\overline{\mathrm{x}}=5.44)$. Ability on gathering appropriate information and making sense of data was marked by all respondents. The less selected abilities are from abstraction $(\overline{\mathrm{x}}=2)$ and, computing and society $(\overline{\mathrm{x}}=2.5)$ dimensions. Ability on filtering information when modelling was selected only by one respondent. Furthermore, correlation between respondents' answers showed that at $1 \%$ level of significance the strong positive relationship is in four pairs: dances subject and primary teacher, informatics (as IT in Table 5) and informatics, language and primary, informatics and informatics \& mathematics (as IT + Maths in Table 5) (colored in yellow in Table 5). At 5\% level of significance the magnitude of the association is also strong positive between four pairs: primary and dances, language and primary, primary and informatics, and moderate positive between primary and primary teachers' answers (colored in orange in Table 5).

Moreover, in order to quantify how much these teachers, agree with each other the Kendall's Concordance Coefficient W was calculated. Kendall's W is 0.265. Thus teachers have a poor agreement with each other. And the mostly rated ability was 1 (mean rank 19.88), the less rated -6 and 10 (mean rank 9.45). Friedman chi-squared $=74.183$, $\mathrm{df}=28$, p-value $=0.0001$. Friedman chi-squared is higher than chi-squared distribution with 28 degrees of freedom critical value at $99 \%$ significance level: $48.278, \alpha=0.01$. Thus we can reject the null hypothesis and thus conclude that there is the agreement between experts.

Table 5

Correlations on teachers indicated abilities they are using in classes

\begin{tabular}{|c|c|c|c|c|c|c|c|c|c|c|c|}
\hline \multicolumn{12}{|c|}{ Correlations (Ah-ties teachers are using) } \\
\hline & & Language & Primay & $\begin{array}{c}\text { Pre- } \\
\text { painary }\end{array}$ & IT & IT & Physics & IT+14tallis & Dances & Primary & I \\
\hline \multirow[t]{2}{*}{ Language } & Comelalivo & 1 & $455^{\circ}$ &, 305 & 219 &,- 0887 &, 194 &, 005 & $3 \mathbf{3 6 2}$ & $510^{-1}$ &,- 15 \\
\hline & $\sin (2-$ & &, 013 & , 108 & 253 &, 652 &, $\mathbf{3 1 3}$ & 979 &, 054 & , 005 & 42 \\
\hline \multirow[t]{2}{*}{ Primary } & Comelatio & $455^{\circ}$ & 1 &,- 051 & $.442^{-}$ &, 029 & ,029 & ,098 &, $461^{+}$ & $391^{\circ}$ & , 05 \\
\hline & $\sin (2-$ &, 013 & &, 791 &, 016 & ,881 & ,881 &, 614 &, 012 &, 036 &, 79 \\
\hline \multirow{2}{*}{$\begin{array}{l}\text { Pre- } \\
\text { pinary }\end{array}$} & Conrelalino &, 305 &,- 051 & 1 & 247 &,- 110 &, 344 &, 033 & ,141 &, 110 & $2 \mathbf{2 8}$ \\
\hline & $\sin (2-$ & , 108 &, 791 & & , 196 & 571 &, 067 &, 864 &, 467 & 571 &, 12 \\
\hline \multirow[t]{2}{*}{ II } & Comelatio & 219 & $442^{\circ}$ & 247 & 1 &, 362 &, 049 & , 081 & 285 & 265 &, 587 \\
\hline & $\sin (2-$ &, 253 &, 016 & ,196 & &, 054 & 8012 &, 678 & , 133 & ,165 &, 00 \\
\hline \multirow[t]{2}{*}{ II } & Comelatio &,- 087 & .029 &,- 110 &, 362 & 1 &,- 137 & $496^{-1}$ & , 127 &,- 005 &, 412 \\
\hline & $\sin (2-$ &, 652 & 881 &, 571 &, 054 & &, 478 & ,006 &, 512 & ,9:00 &, 02 \\
\hline \multirow[t]{2}{*}{ Physics } & Comelation &, 194 &, 029 &, 344 &, 049 &,- 137 & 1 &,- 110 & , 127 & 279 &,- 04 \\
\hline & Sin (2- &, 313 &, 881 &, 067 &, 802 &, 478 & &, 571 & 512 &, 142 &, 83 \\
\hline \multirow[t]{2}{*}{ 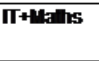 } & Comelation & .005 & .098 &, 033 &, 081 & 496 &,- 110 & 1 & ,141 &,- 042 & 28 \\
\hline & $\sin (2-$ & 979 & .614 & 864 &, 678 &, 006 &, 571 & &, 467 & ,830 & ,12 \\
\hline \multirow[t]{2}{*}{ Dances } & Comelation & .362 &, $461^{\circ}$ & , 141 & 285 & , 127 & , 127 &, 141 & 1 &, $610^{-1}$ &, 33 \\
\hline & $\sin (2-$ &, 054 &, 012 &, 467 &, 133 &, 512 &, 512 & .467 & &, 000 & ,08 \\
\hline \multirow[t]{2}{*}{ Primary } & Comelalio & $.510^{-}$ &, $391^{\circ}$ &, 110 & 265 &,- 005 & 279 &,- 042 &, $610^{-}$ & 1 &,- 11 \\
\hline & Sin (2- &, 005 &, 036 &, 571 &, 165 &, 980 &, 142 &, 830 &, 000 & &, 57 \\
\hline \multirow[t]{2}{*}{ II } & Comelalion &,- 155 & .051 &, 289 &, $587^{-1}$ & $412^{\circ}$ &,- 042 &, 289 & 330 &,- 110 & \\
\hline & Sin (2- &, 422 & ,791 & , 129 &, 001 & .026 &, 830 & ,129 &, 081 &, 571 & \\
\hline
\end{tabular}

${ }^{*}$ Correlation is significant at the 0.05 level (2-tailed).

${ }^{* *}$ Correlation is significant at the 0.01 level (2-tailed). 
Teachers indicated that the most relevant $\mathrm{CT}$ abilities are from algorithms $(\overline{\mathrm{x}}=4.75)$ dimension. However, the most chosen abilities were from other dimensions: to gather appropriate information (Data analysis \& representation), use appropriate algorithmic principles (Computing Artefacts) and, explain how an artefact functions (Evaluation). Three abilities were not selected at all: share the workload by providing individual contributions to overall collaborative effort; foster a constructive collaborative climate by resolving conflicts and facilitating the contributions; exchange knowledge and feedback. All of them are from communication and collaboration dimension. Such abilities are common in group learning approaches.

Moreover, in order to quantify how much these teachers, agree with each other the Kendall's Concordance Coefficient W was calculated. Kendall's W is 0.264. Thus teachers have a poor agreement with each other. And the mostly rated abilities were 1, 7, 28 (mean rank 22.5), the less rated - 20, 21 and 22 (mean rank 9.00). Friedman chi-squared $=59.070, \mathrm{df}=28, \mathrm{p}$-value $=0.001$. As the chi-squared statistic exceeds critical value with 28 degrees of freedom 48.278 at $99 \%(\alpha=0.01)$ significance level, we reject the null hypothesis and conclude that there is the agreement between respondents. Correlations between respondents' answers (in Table 6 colored in yellow) showed that at $1 \%$ level of significance the strong positive relationship is in the following pairs: language and dances subject, pre-primary and informatics (as IT in Table 6), and language and informatics. At 5\% level of significance the magnitude of the association is moderate positive between the following subjects' pairs: primary and pre-primary, informatics and informatics, dances and informatics, informatics \& mathematics and informatics, informatics and informatics (colored in orange in Table 6).

Table 6

Correlations teachers indicated as the most relevant for CT

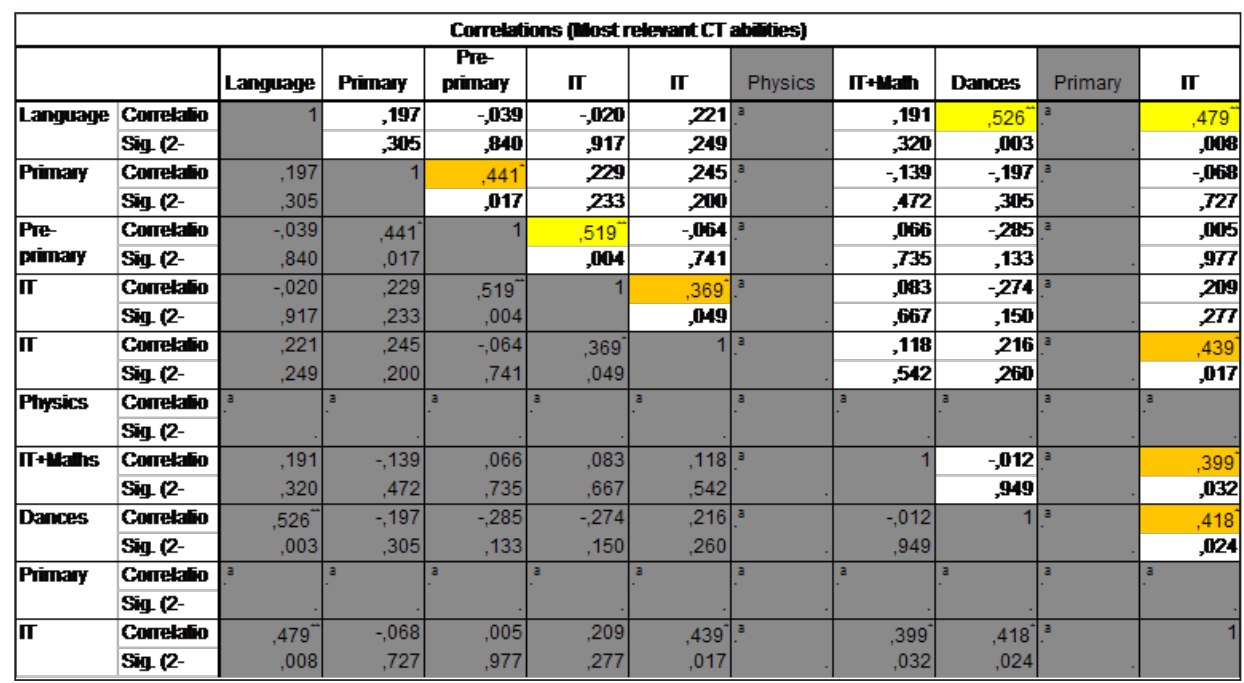

* Correlation is significant at the 0.05 level (2-tailed).

${ }^{* * *}$ Correlation is significant at the 0.01 level (2-tailed). 
Table 7

Correlations of abilities teachers indicated as most relevant for $\mathrm{CT}$ and they are using in classes in total

\begin{tabular}{|c|c|c|c|c|c|c|c|c|c|c|c|}
\hline \multicolumn{12}{|c|}{ Correlations (Using and rekewant) } \\
\hline & & Language & Primary & $\begin{array}{c}\text { Piz- } \\
\text { pimary }\end{array}$ & I & IT & Physics & IT+1kalh & Dances & Primary & IT \\
\hline \multirow[t]{2}{*}{ Language } & Comelatio & 1 & $264^{\circ}$ &, 135 &, 079 &, 078 & ,194 &, 076 &, $440^{-1}$ &, $510^{-1}$ &, 153 \\
\hline & $\sin (2-$ & &, $\mathbf{0 4 5}$ & ,313 & 554 & 561 &, 313 & 569 &, 001 &, 005 & 250 \\
\hline \multirow[t]{2}{*}{ Primary } & Conrelatio & $264^{-}$ & 1 & ,111 &, $367^{-1}$ &, 021 &, 029 &, 076 & 201 & $391^{\circ}$ &, 042 \\
\hline & $\operatorname{Sin}(2-$ &, 045 & &, 407 & ,005 & ,874 & ,881 & 571 & , 129 &, 036 &, 754 \\
\hline \multirow{2}{*}{$\begin{array}{l}\text { Pre- } \\
\text { paimary }\end{array}$} & Conrektio &, 135 & .111 & 1 &, $387^{-1}$ &,- 091 &, 344 & ,052 &,- 069 & , 110 &, 148 \\
\hline & $\sin (2-$ &, 313 & .407 & &, 003 &, 495 &, 067 &, 697 &, 608 & 571 & 266 \\
\hline \multirow[t]{2}{*}{ 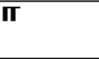 } & Conrelation &, 079 & $367^{-1}$ &, $387^{-1}$ & 1 &, $338^{-1}$ &, 049 &, 097 &,- 008 & 265 &, $389^{-7}$ \\
\hline & $\sin (2-$ &, 554 &, 005 &, 003 & &, 009 & ,8:12 &, 468 &, 953 &, 165 &, 003 \\
\hline \multirow[t]{2}{*}{ II } & Comelation & .078 &, 021 &,- 091 &, $338^{-}$ & 1 &,- 137 &, $296^{\circ}$ &, 170 &,- 005 & $.411^{-}$ \\
\hline & $\operatorname{Sin}(2-$ &, 561 & .874 &, 495 &, 009 & &, 478 &, 024 & 201 & ,9800 &, 001 \\
\hline \multirow[t]{2}{*}{ Physics } & Conrelation &, 194 &, 029 &, 344 &, 049 &,- 137 & 1 &,- 110 &, 127 & 279 &,- 042 \\
\hline & $\sin (2-$ &, 313 & ,881 &, 067 &, 802 &, 478 & &, 571 &, 512 &, 142 & ,830 \\
\hline \multirow[t]{2}{*}{ IT+4taths } & Comelation & .076 & .076 &, 052 & 097 & 296 &,- 110 & 1 &, 069 &,- 042 & $346^{-1}$ \\
\hline & $\sin (2-$ &, 569 & .571 & ,697 &, 468 &, 024 &, 571 & & ,609 & ,830 &, $\mathbf{0 0 8}$ \\
\hline \multirow[t]{2}{*}{ Dances } & Comelation & $440^{-1}$ & 201 &,- 069 &,- 008 & .170 & , 127 &, 069 & 1 &, $610^{-1}$ &, $374^{-1}$ \\
\hline & Sin (2- &, 001 &, 129 &, 608 &, 953 &, 201 &, 512 &, 609 & &, 000 &, 004 \\
\hline \multirow[t]{2}{*}{ Primary } & Conrelation &, $510^{-7}$ & 391 &, 110 &, 265 &,- 005 &, 279 &,- 042 & $.610^{-}$ & 1 &,- 110 \\
\hline & Sin (2- &, 005 &, 036 &, 571 & .165 &, 980 &, 142 &, 830 &, 000 & &, 571 \\
\hline \multirow[t]{2}{*}{ II } & Comelation &, 153 &, 042 & , 148 &, $389^{-}$ & $.411^{-1}$ &,- 042 & $.346^{-1}$ & $374^{-}$ &,- 110 & 1 \\
\hline & $\sin (2-$ &, $250 \mid$ &, 754 &, 266 &, 003 &, 001 &, 830 &, 008 &, 004 & ,571 & \\
\hline
\end{tabular}

* Correlation is significant at the 0.05 level (2-tailed).

${ }^{* *}$ Correlation is significant at the 0.01 level (2-tailed).

In total, respondent opinions on $\mathrm{CT}$ abilities they are using and what are the most relevant $\mathrm{CT}$ abilities (Table 7), strong positive correlation at $1 \%$ level (colored in yellow in Table 7) was indicated between two pairs: daces and primary, language and primary. One of informatics teacher's answers had moderate positive association with four teachers' answers: informatics, other informatics, dances and informatics \& mathematics, Primary and pre-primary subjects' teachers' opinions had the similar association with the same informatics teacher, and in pairs of language and dances teachers, as well as, between two informatics teachers. At 5\% level (colored in orange in Table 7) of significance the magnitude of the association is weak and moderate positive between the following subjects' pairs respectively: primary and primary, informatics and informatics \& mathematics.

\section{Conclusions and Discussion}

CT approach is mostly related to informatics and many researchers defined CT in a way of drawing from programming and computing concepts (Tang et al., 2020). Three of respondents (out of thirteen) who had significant relationship with author's opinion were informatics teachers. Informatics teachers have some prior knowledge on CT and algorithmic thinking. Such result leads to the assumption that absence of correlation with others teachers is due to the lack of explanation on CT and abilities, or low relevance of CT to other subjects. 
Due to the most of CT dimensions' abilities are common in other pedagogical approaches (such as problem-solving), the results on teachers' used abilities at teaching their subject confirmed that guess. As the CT abilities examined overlapping with abilities from other commonly used pedagogical approaches such as regarded CT as a set of competences requiring students to develop both domain-specific knowledge and problem-solving skills (Tang et al., 2020), it was not surprise that the most selected abilities that are often used in classes are from data analysis and representation, as well as, communication and collaboration dimensions.

Teachers from different disciplines had a poor agreement with each other on CT abilities relationship with class activities, however some had strong or moderate agreements between each other. Teachers' perceptions and believes of CT abilities implementation in the classroom differ in subject they teach. However, the difference is not so big. Even different subject teachers have a lot of in common, such as dance and informatics, or informatics and primary school teacher. Future work includes the analysis and extension of the identified CT components regarding different subjects in order to determine what components are common in particular subjects.

The results showed that $\mathrm{CT}$ could be integrated by proposed class activities in different subjects however deeper efforts should be invested for CT integration research in different subjects as well as analysis of how to encourage learners to apply CT skills into learning other disciplines needs further investigation and is positioned as future work.

The limitation of this paper is that there was no focus on teacher's school levels or position, only, on subjects. This is a small study with little amount of participants. However, it is believed that the participants were quite representative as they all were interested and had some experience in STEAM disciplines integration, and know or believe that it could help improve learning.

Also, the opinions of teachers are biased by the course they visited. So the results evaluate also the course. And it is questionable how relevant the opinions of teachers are after just one-day training.

\section{Acknowledgments}

This project has received funding from European Social Fund (project No 09.3.3LMT-K-712-02-0066 under grant agreement with the Research Council of Lithuania (LMTLT).

\section{References}

Bati, Kaan \& Yetişir, Mehmet \& Çalişkan, Ilke \& Gunes, Gokhan \& Saçan, Esma. (2018). Teaching the concept of time: A steam-based program on computational thinking in science education. Cogent Education. 5. 1-16. DOI: 10.1080/2331186X.2018.1507306.

Conde, M. Á., Fernández, C., Alves, J., Ramos, M. J., Celis-Tena, S., Gonçalves, J., ... \& Peñalvo, F. J. G. (2019). RoboSTEAM-A Challenge Based Learning Approach for integrating STEAM and develop Com- 
putational Thinking. In: Proceedings of the Seventh International Conference on Technological Ecosystems for Enhancing Multiculturality (pp. 24-30). ACM.

Curzon, P., McOwan, P.W. (2017). The Power of Computational Thinking: Games, Magic and Puzzles to Help You Become a Computational Thinker. World Scientific.

F.Z.M. Zaki, S.L. Wong, and M.R. Yaakub, A Review of Common Features in Computational Thinking Frameworks in K-12 Education. IOP Conference Series: Materials Science and Engineering. Vol. 551. No. 1. IOP Publishing, 2019.

Fessakis, G., \& Prantsoudi, S. (2019). Computer Science Teachers' Perceptions, Beliefs and Attitudes on Computational Thinking in Greece. Informatics in Education, 18(2), 227-258.

Grover, S., Pea, R. (2013) Computational thinking in K-12: A review of the state of the field. Educational Researcher, 42(1), 38-43.

Guenaga, Mariluz, et al. Make world, a collaborative platform to develop computational thinking and STEAM. In: International Conference on Learning and Collaboration Technologies. Springer, Cham, 2017. p. 50 59.

ISTE, CSTA. (2011). Computational Thinking in K-12 Education Leadership Toolkit.

Ju keviciene, A. (2019). Teaching content development for Computational thinking skills implementation. ICERI 2018 Proceedings, 1364-1372.

Juškevičienè, A. (2020). Developing Algorithmic Thinking Through Computational Making. In: Data Science: New Issues, Challenges and Applications (pp. 183-197). Springer, Cham. Ju keviciene, A., \& Dagiene, V. (2018). Computational Thinking Relationship with Digital Competence. Informatics in Education, 17(2), 265-284.

Krauss, J., Prottsman, K. (2017). Computational Thinking and Coding for Every Student. The Teacher's Getting-Started Guide. Corwin Press Inc.

Lytle, N., Cateté, V., Boulden, D., Dong, Y., Houchins, J., Milliken, A., \& Barnes, T. (2019, July). Use, Modify, Create: Comparing Computational Thinking Lesson Progressions for STEM Classes. In: Proceedings of the 2019 ACM Conference on Innovation and Technology in Computer Science Education (pp. 395-401). ACM.

Mislevy, R. J., Behrens, J. T., Dicerbo, K. E., \& Levy, R. (2012). Design and discovery in educational assessment: Evidence-centered design, psychometrics, and educational data mining. JEDM Journal of Educational Data Mining, 4(1), 11-48.

Moreno-León, J., Román-González, M., \& Robles, G. (2018, April). On computational thinking as a universal skill: A review of the latest research on this ability. In Global Engineering Education Conference (EDUCON), 2018 IEEE (pp. 1684-1689). IEEE.

Moreno-León, J., Román-González, M., \& Robles, G. (2018, April). On computational thinking as a universal skill: A review of the latest research on this ability. In Global Engineering Education Conference (EDUCON), 2018 IEEE (pp. 1684-1689). IEEE.

Pöllänen, S., \& Pöllänen, K. (2019). Beyond Programming and Crafts: Towards Computational Thinking in Basic Education. Design and Technology Education, 24(1), n1.

Psycharis, S. (2018). STEAM in education: A literature review on the role of computational thinking, engineering epistemology and computational science. Computational steam pedagogy (CSP). Sci. Cult, 4(2), 51-72.

Sentance, S., \& Csizmadia, A. (2017). Computing in the curriculum: Challenges and strategies from a teacher's perspective. Education and Information Technologies, 22(2), 469-495.

Tang, X., Yin, Y., Lin, Q., Hadad, R., \& Zhai, X. (2020). Assessing computational thinking: A systematic review of empirical studies. Computers \& Education, 103798.

Weigend, M., Pluhár, Z., Juškevičienè, A., Vaníček, Ji., Ito, K., \& Pesek, I.. (2018). Constructionism in the classroom: Creative learning activities on computational thinking. Constructionism 2018: Constructionism, Computational Thinking and Educational Innovation: Conference Proceedings, 891-907.

Williams, H. (2017). No Fear Coding: Computational Thinking Across the K-5 Curriculum (p. 176). Portland, Oregon: International Society for Technology in Education.

Wing, J.M. (2008). Computational thinking and thinking about computing. Philosophical Transactions of the Royal Society A: Mathematical, Physical and Engineering Sciences, 366(1881), 3717-3725.

World Economic Forum (WEF). (2016, January). The future of jobs: Employment, skills and workforce strategy for the fourth industrial revolution. In World Economic Forum.

Zscheischler, J., Rogga, S., \& Busse, M. (2017). The Adoption and Implementation of Transdisciplinary Research in the Field of Land-Use Science - A Comparative Case Study. Sustainability, 9(11),1926. 
A. Juškevičienė is a doctor of technological sciences (informatics engineering). She is the researcher at the Vilnius University Institute of Data Science and Digital Technologies. The areas of her scientific interest focus on technology enhanced learning, computational thinking, hands-on activities. She has been working very active on several national projects, helps to organize seminars and conferences. She has published a number of scientific papers and publications in popular magazines, participated in a number of large scale EU-funded R\&D projects. 